\title{
The Mental Health of Refugees during a Pandemic: The Impact of COVID-19 on Resettled Bhutanese Refugees
}

\author{
Tanner McGuire ${ }^{1}$ - Daniel Yozwiak ${ }^{1}$ - Julie M. Aultman ${ }^{1}$
}

Received: 2 February 2021 / Revised: 22 July 2021 / Accepted: 27 July 2021 /

Published online: 13 September 2021

(c) National University of Singapore and Springer Nature Singapore Pte Ltd. 2021

\begin{abstract}
This paper is the first of two in a series. In this paper, we identify mental health needs and challenges in the age of COVID-19 among Nepali-speaking, Bhutanese resettled refugees in the USA. We argue for a public health justice framework that looks critically at social determinants impacting mental health (SDIMH) barriers, which negatively impact our Bhutanese population, and serves as a theoretical foundation toward public policy and law that will inform healthcare decisions and fair treatment of resettled refugees at the clinical bedside and in the community. We first describe our Bhutanese refugee population and the critical mental health issues that, for many, originated during political persecution and violent ethnic cleansing initiatives, or while living in refugee camps prior to resettlement to the USA. We present a social justice framework emerging from an extensive literature review and incorporating core social determinants specific to mental health in the age of COVID-19, which are guided by the social determinants of economic stability; neighborhoods and physical environment; education; nutrition and exercise; community and social context; healthcare system; and legal system. We illustrate specific SDIMH of our resettled Bhutanese refugees during the pandemic, followed by a second paper that details recommendations for applying the SDIMH in a collective effort to address specific barriers to mental healthcare and support.
\end{abstract}

Keywords Justice $\cdot$ Social determinants $\cdot$ Refugee $\cdot$ Mental health $\cdot$ Pandemic . COVID-19

Increased mental health and suicide risks among resettled refugees in the USA pose extensive legal, ethical, and clinical challenges for healthcare professionals, legal

Julie M. Aultman

1 Northeast Ohio Medical University, Rootstown, OH, USA 
advisors, community leaders, and advocates. These challenges stem from sociocultural differences, legal obstacles, and medical histories that have been complicated by refugee encampment and the resettlement process. ${ }^{1}$ The mental health of Nepalispeaking refugees especially has been impacted by persecution and displacement from Bhutan, challenging living conditions in the Nepali refugee camps, and interdependent social determinants of health during resettlement. Additionally, during the COVID-19 pandemic, refugees in the USA are at higher risk of getting COVID19 because of living or working conditions, and other social determinants (Centers for Disease Control and Prevention, n.d.). The pandemic has only exacerbated specific social determinants impacting mental health (SDIMH) among the Nepalispeaking refugee community.

Rates of mental illness among the Nepali-speaking community surveyed by the Centers for Disease Control (CDC) show rates of depression and anxiety at $21 \%$, and a rate of suicide nearly two times that of the general US population (Ao et al. 2016). The Ohio Mental Health and Addiction Services found mental illness rates among the Nepali-speaking community in Ohio, the third largest receiver of refugees in the USA, ${ }^{2}$ much higher than the national average with $30 \%$ suffering from symptoms of anxiety and 26\% from depression (Adhikari et al. 2015). Additionally, 21\% in Ohio reported their family members had completed suicide, compared to only $5 \%$ in the national CDC study (Adhikari et al. 2015). Though these rates are high, they are likely underreported due to stigma and linguistic barriers (Adhkari et al. 2015; Ao et al. 2016). Thus, depending on the location of resettled Bhutanese refugees, rates of mental health issues, including suicidality, can be three times as high as the rest of the population. These exceedingly high rates call for a careful examination by resettlement communities and healthcare providers of contributing factors and potential solutions that yield improved health outcomes and social justice.

Our discussion of these issues will take place over the course of two separate articles. In this first article, we explore the historical and cultural background of the Bhutanese refugee community and the social determinants which impact their mental health. In the second article, we examine the current treatments and

\footnotetext{
${ }^{1}$ We will refer to our focus population throughout this manuscript as Bhutanese refugees or resettled Bhutanese refugees. We recognize that many of our refugees are Nepali-speaking and/or Nepali-born; others speak several languages and were born in Bhutan. Some have been born in refugee camps or in their resettled communities and will refer to themselves as Nepalese Bhutanese Americans, for example. We recognize that a person's identity is tied to their family, place of birth, place of origin (e.g., refugee camp), and/or their citizenship.

${ }^{2}$ In addition to being the location of this research team, Ohio is a top refugee-receiving state and the locale where a vast number of Bhutanese refugees have resettled in recent years. In 2017, Ohio received over 2000 refugees, the majority of whom were Bhutanese (Galvin 2018), followed by the resettlement of 1408 refugees in 2018 (National Immigration Forum 2019). And last year, during fiscal year 2019, Ohio welcomed another 1400 refugees (Krogstad 2019). To put these numbers into perspective, we can compare them to global statistics published by the United Nations High Commissioner for Refugees (UNHCR, n.d.b). In 2017, Ohio resettled 2085 refugees-more than Ireland (308), Spain (1373), Italy (1392), and New Zealand (1309). Canada resettled about 4000 refugees the same year. In 2018, France resettled almost 5000 refugees, Germany resettled 4277, and Japan resettled 37. Even when placed on a global scale, Ohio's resettled refugee population is significant in size and can provide great insight into the struggles faced by refugee communities nationwide.
} 
alternative approaches to healing mental illness and discuss the many ways in which our healthcare systems, governments, local communities, and leaders can better support the Bhutanese refugee community.

The COVID-19 pandemic has posed significant barriers to provide care and social support; increased issues of isolation and addictive behaviors, heightened anxiety, fear, and experiences of discrimination, among other barriers, have impaired progress toward social justice. As Gostin and Powers (2006, 1054) write, "public health that is based on social justice can address health determinants and plan for health emergencies with 'an eye on the needs of the most vulnerable"'. In light of the recent pandemic, it is essential to adopt a public health justice framework that examines the SDIMH of Bhutanese refugees as a vulnerable population and the clinical, legal, and ethical needs of personalized mental healthcare.

\section{Methodology}

To establish an essential framework, we first conducted a qualitative systematic review of the literature by synthesizing and critically appraising evidence from primarily qualitative studies and theoretical ethical and social science examinations of refugee health, resettlement processes and experiences, and literature that has informed policy and practice of healthcare delivery, identifying social determinants of health, and international and US policies, guidelines, and definitions involving refugee, immigrant, and asylee-seeking populations. A narrowed search in the effort to answer research questions specific to the Nepali-speaking Bhutanese refugee and resettled refugee populations was conducted; parts of our systematic review were to discover gaps in the literature and to determine whether studies conducted in one cultural context (Nepali-speaking Bhutanese resettled refugees living in the USA) show different results from other cultural contexts (e.g., other refugee populations and resettlement locations) (Davis et al. 2014). All three authors came to a consensus as to which pieces of literature supported the proposed questions, ethical arguments, and insights surrounding our population under study. We also identified and verified the evidence-based literature (primarily qualitative and descriptive peerreviewed articles) we used to substantiate our key claims. Additionally, we include reported experiences and regional information acquired through informal correspondence with experts from a local agency, Asia, Inc., who provides legal, financial, and health assistance to Asian refugee populations.

Our findings reveal that our focal population has unique experiences due to their culture, resettlement environment, experiences of COVID-19 testing, treatment, and prevention, but also very similar experiences to other resettled refugee populations and cultures within and external to the USA. The purpose of this manuscript is to illustrate the unique experiences of this population under study, but to equally show how our identified social determinants of health are applicable to other resettled refugee and asylee-seeking populations. 


\section{Foundations in Public Health Justice}

As Gostin and Powers (2006) describe, justice in public health includes two aspects: health improvement for the population and fair treatment of the disadvantaged. Bhutanese refugees are a disadvantaged population requiring fair treatment and not simply in the form of opportunities to acquire healthcare services. Fair treatment requires a coordinated effort on the part of federal, state, and local governments, healthcare professionals, and community leaders. These entities must identify and address SDIMH, and the causes of ill health during a pandemic, while strategically delivering the resources necessary to achieve fairness for disadvantaged groups. Here, we focus on mental health needs in the age of COVID-19 with one of many disadvantaged populations. Based on our extensive literature review, we argue for a public health justice framework that looks critically at social determinants negatively impacting the mental health of our Bhutanese population living in the USA. We further argue for public policies and laws that will inform healthcare decisions and fair treatment at the bedside and in the community. The following paper first describes our Bhutanese refugee population and the critical mental health issues that, for many, originated during political persecution, violent ethnic cleansing initiatives, and/or while living in refugee camps prior to resettlement. We then present the SDIMH specific to our resettled Bhutanese refugees and discuss their harmful impact during this public health crisis. The SDIMH further informs our final section which examines public health justice through the lenses of law, ethics, and medicine, and our proposed call to action toward health improvement and fair treatment.

\section{Bhutanese Refugees: a Disadvantaged Population}

The Nepali-speaking Bhutanese refugees are people of Nepalese origin who began immigrating to southern Bhutan as early as the seventeenth century. The country of Bhutan originally welcomed the spirited and industrious Nepalese immigrants, assisting them with jobs, education, and food (Ikram 2005). They soon became referred to as the Lhotshampas, meaning "people of the south," and constituted between an estimated $25-53 \%$ of the total Bhutanese population (Rizal 2004). Their ethnic and cultural differences starkly separated them from the other Bhutanese; these differences included their own religion, dialect, habits, dress and apparel, traditions, and culture (Ikram 2005).

\section{Political Unrest}

As the Lhotshampas in southern Bhutan began to have a more prominent influence, ruling elites such as the Ngalung ethnic group feared the possibility of losing political, economical, and cultural dominance (Rizal 2004). Bhutan's chauvinistic King Jigme Wangchuck and Druk regime soon enacted and enforced discriminatory laws 
in the 1980s including The Citizenship and Marriage Acts, Driglam Namzha, and The Green Belt Policy. The Citizenship and Marriage Acts resulted in over 100,000 losing their right to Bhutanese citizenship, including women, men, and children; this meant no right to education, medical treatment, etc. (Ikram 2005). This deprivation of citizenship worsened under the Driglam Namzha, the "One Nation, One People" policy, which sought to erode the identity and diversity of the Lhotshampas by enforcing ethnic Ngalung customs. Mandatory requirements consisted of etiquette and dress, the use of the Dzongkha (the official language), and the practice of the Drukpa Kargupa Buddhist ideology. Heavy fines and arrests were imposed for noncompliance to ensure censoring of Lhotshampa identity and culture (Rizal 2004). The Green Belt Policy, though not implemented, aimed to financially restrain the Lhotshampas by proscribing human habitation within one kilometer of the border of India. This area included one third of the Lhotshampas' lands and homes (Rizal 2004).

Many Lhotshampas protested in response to their rights, safety, and welfare being abrogated. Yet, stronger governmental powers placed these protestors in prison, where they were severely tortured, beaten, raped, deprived of food and clothing, and forced to violate cultural and religious norms (Shrestha et al. 1998; Thapa et al. 2003). Other Lhotshampas fled to Nepal for refuge after government forces destroyed their homes, threatened their lives, and compelled them to sign voluntary emigration forms. One Bhutanese refugee stated, "The army took all the people from their houses...They snapped our photos. The man told me to smile...to show that I was leaving my country willingly, happily, that I was not forced to leave" (Frelick 2011). More than 100,000 Bhutanese refugees were forced to flee from their homes to Nepal.

\section{Life in a Refugee Camp}

For the next sixteen to twenty years, the Bhutanese refugees lived in various refugee camps throughout Nepal with new challenges to confront (Adhkari et al. 2015). Although many had left the abuse and violence of the Bhutanese government, the refugees now faced various forms of violence and crime in the camps, in addition to mental illness, malnutrition and poor health, and loss of basic freedoms (Aultman 2019).

Physical and sexual violence and abuse continued in the Nepali refugee camps, particularly affecting Bhutanese women and children (Varia and Caouette 2003). After receiving many reports of sexual exploitation, United Nations High Commissioner for Refugees (UNHCR) found refugee women and children who had suffered sexual assault and domestic violence from others in the camps; these perpetrators included refugee aid workers, local Nepalese, and other refugees (Varia and Caouette 2003). Those who sought help and justice often faced further humiliation and shame when cramped quarters and long lines at the hospital failed to allow for any privacy (Varia and Caouette 2003).

Scars left from the physical, sexual, and psychological abuses experienced in Bhutan resulted in new mental health challenges for the Bhutanese refugees to 
confront in the refugee camps. Such lifelong mental health challenges include posttraumatic stress disorder (PTSD), persistent pain, depression, generalized anxiety, phobias, and dissociative disorders (Mills et al. 2008; Van Ommeren et al. 2001). Victims of torture in Bhutan experienced even worse symptoms of PTSD, depression, and anxiety (Shrestha et al. 1998). Suicide and attempted suicide among the Bhutanese refugees in the camps often occurred as a result of mental health challenges (Schininà et al. 2011).

Bhutanese refugees also experienced malnutrition and many health challenges from scarce resources in the camps. Deficiencies of important micronutrients such as riboflavin, vitamin $\mathrm{A}$, folate, vitamin $\mathrm{B}_{12}$, and iron led to anemia and angular cheilitis (Blanck et al. 2002; Woodruff et al. 2006). One cross-sectional study by the Center for Disease Control (2008) found a total of $26.9 \%$ of children with chronic malnutrition and an additional $4.2 \%$ with severe chronic malnutrition. Twenty-five percent of children were underweight, $43.3 \%$ of children had anemia, $30 \%$ of children had diarrhea, and $28.8 \%$ had an acute respiratory illness.

Other basic human rights were also taken away, such as not being allowed to legally work, pursue higher education, or have a sense of independence (Adhkari et al. 2015; Reiffers et al. 2013). The refugees' focus was on obtaining nutritious food, healthcare, clean drinking water, electricity, etc. (Pulla 2016), making it difficult for these refugees to find meaning in their life (Reiffers et al. 2013) and contributing to their unique mental health challenges.

\section{Challenges of Resettlement}

After over twenty years of living in refugee camps, plans were made in 2007 for Bhutanese refugees to begin resettling in various countries. Between 2007 and 2019, the UNHCR (2019) reports the resettlement of 113,000 refugees from Nepal to countries including the USA, Australia, Canada, Denmark, Netherlands, New Zealand, Norway, and the UK. Ninety-six thousand of these refugees resettled in the USA alone.

According to the Migration Policy Institute, the UNHCR closed its resettlement program in Nepal in 2018 which greatly reduced the number of Bhutanese refugees admitted into the USA thereafter (Blizzard and Batalova 2019). While approximately 2228 Bhutanese refugees were admitted into the USA during fiscal year 2018, only 19 Bhutanese refugees had been granted admission during the first seven months of fiscal year 2019 (Blizzard and Batalova 2019). Bhutanese refugees participated in pre-departure orientations lasting one to five days involving classes and brief video presentations by resettled refugees of the same ethnicity, and they received a UNHCR guidebook of the resettlement process (Kim et al. 2017). They were also required to take out an interest-free loan for transportation to the host country which must be paid back in full within three and a half years (UNHCR 2014).

Prior to entrance into the USA, a refugee must undergo certain screenings and evaluations, including Refugee Status Determination (RSD) (UNHCR, n.d.a). An overseas refugee-seeking entry into the USA must first complete the RSD interview 
with the Department of Homeland Security/U.S. Citizenship and Immigration Services (USCIS) (U.S. Citizenship and Immigration Services 2013). If the USCIS officer determines that the interviewee meets the legal definition of a "refugee," then that person may be granted refugee status and obtain temporary/permanent residency in the USA. ${ }^{3}$ If, however, an applicant is denied entry to the USA as a refugee, there is no way to appeal the decision (unless new/previously unavailable information is revealed) (Refugee Council USA, n.d.).

Upon arriving in the USA, refugees must obtain a medical examination to ensure good health, prevent disease, and to become familiar with the US' healthcare system. Although this medical exam is intended to be a comprehensive exam of well-being and health, a mental health exam is not required as part of this medical examination, but is encouraged with available services (Kobau et al. 2012). Examiners focus on contagious diseases that could spread in the general population, such as infectious diseases. Yet, other medical needs, including any mental health challenges, often go unseen because of the lack of time, resources, or reporting among refugees during initial screening. After passing this medical screening, sponsoring agencies ensure basic needs for a minimum of thirty days and maximum of 90 days; this help includes housing, furnishings, food, clothing, enrollment in English courses, and transportation to job interviews (UNHCR 2014). Although some receive help from resettlement agencies, one study in Ohio showed $70 \%$ of resettled Bhutanese refugees claimed little to no help from charities or other agencies and $69.5 \%$ claimed little help from the government (Adhikari et al. 2015). Many, however, express the need for additional help with healthcare, Medicaid, education, employment, and financial assistance which reflects a disconnect between the services provided and the ability of resettled Bhutanese refugees to access these services.

Throughout the resettlement process, many challenges arise that affect Bhutanese refugee mental health. Ethno-cultural communities dissolve as refugees resettle to different states and towns, resulting in the loss of community networks and their individual and group identity (Schininà et al. 2011). Overall, however, they are grateful to be treated with greater acceptance and dignity (Hauck et al. 2014) and many consider their resettlement successful, when defined as being able to live in a country without fear (Australian Survey Research Group 2010). Nevertheless, due to individuals and their families' experiences of oppression and marginalization, challenging living conditions in refugee camps, and loss of physical, mental/emotional, spiritual, and social health prior to resettlement, it is critical that we acknowledge their unique history and the impact this history has on their health, especially their mental health in the age of COVID-19.

\footnotetext{
3 Under US law, the term "refugee" means: “... any person who is outside any country of such person's nationality or, in the case of a person having no nationality, is outside any country in which such person last habitually resided, and who is unable or unwilling to return to, and is unable or unwilling to avail himself or herself of the protection of, that country because of persecution or a well-founded fear of persecution on account of race, religion, nationality, membership in a particular social group, or political opinion..." (see 8 U.S.C. § 1101(a)(42) (2020)). Through the efforts of the UN Refugee Agency, the definition of a refugee - and the overall administrative process - is similar in all participating nation states (UNHCR, n.d.a).
} 


\section{Social Determinants Impacting Mental Health in the Age of COVID-19}

Although resettlement is often a step closer to safety and opportunity, resettled Nepalispeaking refugees face unique challenges surrounding social determinants impacting mental health (SDIMH) and overall well-being (Ao et al. 2016; Aultman 2019). The negative effects of SDIMH have been aggravated during the COVID-19 pandemic and include challenges in economic stability, neighborhoods and physical environments, education, food, community and social context, and the healthcare system (Artiga and Hinton 2018). Examples include acculturation stress, learning English and gaining more education, learning new transportation systems, acquiring safe housing, having access to healthcare and legal services, accessing healthy foods and safe water sources, finding employment and making income, and facing discrimination. The following section utilizes a social determinants of health framework to examine the elements that contribute to poor mental health among Nepali-speaking Bhutanese refugees living in the USA, as well as how mental illness might be exacerbated by the current coronavirus pandemic. The seven core elements of this framework include economic stability, neighborhoods and physical environment, education, nutrition and exercise, community and social context, the healthcare system, and legal system. We developed these based on our qualitative systematic literature review on social determinants of health and information acquired from key informants. While we describe these elements in separate sub-sections, these elements do not always have distinct boundaries; the social determinants can overlap with common features as depicted in Fig. 1.

In each of the following sections, we present a general perspective of the SDIMH that is applicable to multiple refugee and asylee-seeking populations. We also present a specific framework that presents those social determinants that are specific to resettled Bhutanese refugee populations (including those who refer to themselves as immigrants and "new" Americans) living in the USA in the age of COVID (Fig. 2). Sub-sections specific to COVID are identified below and also illustrated in Fig. 2.

Figure 2 presents the social determinants impacting Bhutanese refugee mental health during COVID-19, including unemployment and financial barriers; living conditions and caring for family; communication and education technology; hunger and addiction; discrimination and support systems; health coverage; and legal resources and refugee status. These mental health social determinants in the age of COVID-19 are described in sub-sections of this paper and embedded in the larger context of social determinants. These categories emerged from our literature review as well as from our advocacy and community engagement; they represent our scholarly efforts and we recognize that additional social determinants central to mental health and our target population might be present. 


\section{Social Determinants Impacting Mental Health}

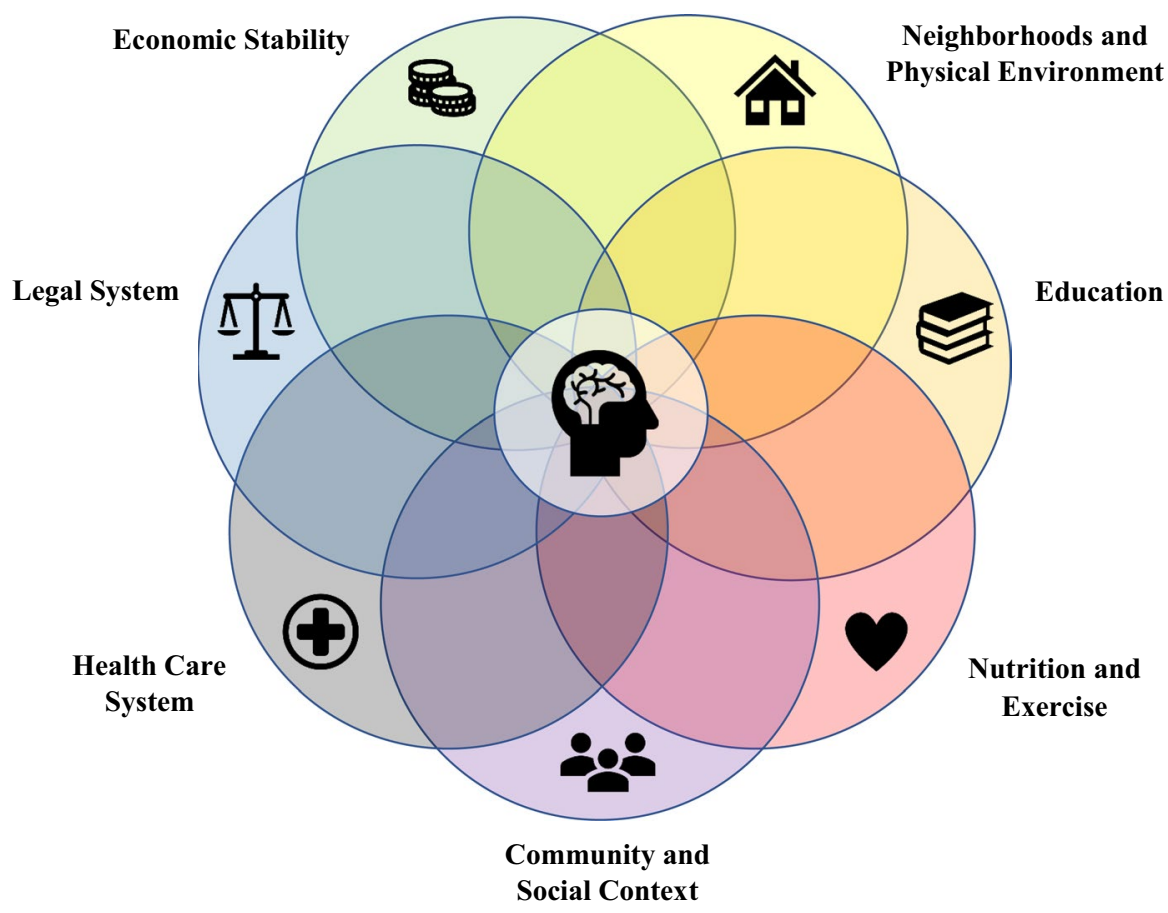

Fig. 1 Social determinants impacting mental health

\section{Economic Stability}

\section{Employment}

Resettled Bhutanese refugees may struggle to secure employment due to discrimination, cultural differences, difficulty communicating in English, and networking. Bhutanese refugees often report feeling discriminated against when trying to find work because of their accent, language barriers, and cultural background (Hauck et al. 2014; Pulla 2016). This constant economic instability results in additional stress when paying for housing, food, transportation, and other expenses. As a result, both parents often work, or other family members delay their education to work (Hauck et al. 2014). Even if both parents can find work, jobs are usually short-term and low-paying, and financial needs are rarely met. One study among resettled Bhutanese refugees in Houston, Texas, found that $33 \%$ had an annual household income less than $\$ 15,000$, and only $2 \%$ made more than $\$ 50,000$ (Misra et al. 2016). The Migration Policy Institute (MPI) found that the median household income fell below $\$ 20,000$ (Capps et al. 2015). The difficulty securing employment, combined with 


\section{Social Determinants Impacting Bhutanese Refugee Mental Health During COVID-19}

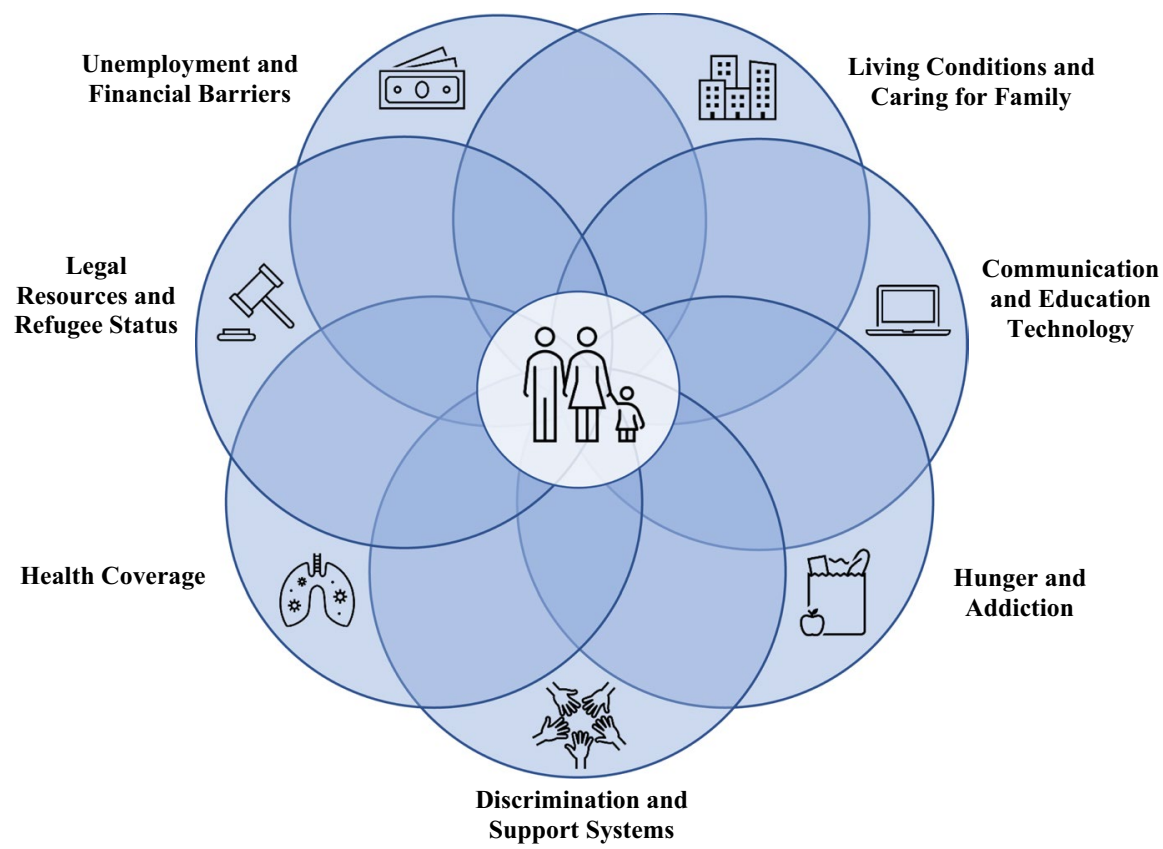

Fig. 2 Social determinants impacting Bhutanese refugee mental health during COVID-19

low wages, has resulted in the majority of resettled Bhutanese refugees living below twice the federal poverty level (Capps et al. 2015). Male Bhutanese specifically experience economic stressors related to employment and providing for the family, and these risk factors lead many to feel burdensome or alienated from family and friends (Ellis et al. 2015).

Unemployment can have a devastating effect on Bhutanese families, particularly those who have difficulty navigating the state systems to report their status and obtain unemployment benefits. Thus, this is another challenge for mental health systems and providers. Previous studies revealed that suicide risk was elevated 20-30\% during 2000 to 2011, when unemployment rates were high (Kawohl and Nordt 2020). Comparatively, part-time and full-time employment has been shown to correlate with increased psychological well-being (Subedi et al. 2019). These effects of unemployment are likewise exacerbated by the COVID-19 pandemic.

\section{Unemployment and Financial Barriers}

The COVID-19 pandemic has increased unemployment rates and likely decreased access to resources such as communication technologies, nutritious foods, and 
transportation among resettled refugee communities. Our refugee and migrant populations are specifically susceptible to unemployment, which can have a devastating effect on their mental health and contribute to feelings of hopelessness and suicide. In the USA, if all of the standard eligibility requirements are met, refugees can obtain unemployment benefits, including pandemic unemployment assistance under the CARES Act (Smith 2020; U.S. Citizenship and Immigration Services 2020). Still, navigating the unemployment application process and securing benefits is not an easy task, especially for an applicant with limited English proficiency and/ or limited computer literacy. For example, the Ohio Department of Job and Family Services (2020) website does not have translation services for Nepali, one of the languages commonly spoken by the state's Bhutanese refugees. Other resettled Bhutanese refugees, although employed, may be on the front lines as essential workers (grocers, police, first responders) and are more susceptible to COVID-19, despite their understanding of precautionary measures and risk of exposure.

\section{Neighborhood and Physical Environment}

\section{Housing, Transportation, and Safety}

Access to parks, playgrounds, community centers, grocery stores, and healthcare centers directly influences SDIMH and overall well-being. Those resettling Bhutanese refugees usually strategically place them in communities with public transportation and opportunities to access vital resources (e.g., grocery stores) on foot. Those US cities that offer support generally make an effort to ensure refugee safety and security by having a law enforcement presence and access to emergency personnel (e.g., EMTs). When identifying communities for resettlement programs, community leaders and government officials also consider where resettled refugees can live together in the same or surrounding neighborhoods for further social support and a sense of security. However, as with any urban environment, it is not always easy to provide safe surroundings and accessible resources. Unstable and unsafe housing and neighborhoods among resettled refugees has been associated with stress and negative mental health outcomes (Ziersch and Due 2018) and is closely linked to education, employment, social inclusion, and physical/mental health (Ziersch et al. 2017).

\section{Parks, Gardens, and Recreation}

As a result of the resettled Bhutanese refugees' history in agriculture, little to no access to land for farming and gardening is a challenge in US cities. Additionally, access to produce may be scarce for resettled Bhutanese refugees living near convenience stores with a limited food supply, rather than larger grocery storesanother detriment to Bhutanese who thrive on produce. However, as the community grows, it is not uncommon for the Bhutanese to become store owners who strive to increase access to food products (especially familiar ingredients that cannot be 
commonly found in a convenient store). Unfortunately, store owners place themselves and their families at risk as essential workers during a pandemic and might not have been afforded the guidance and resources (e.g., plastic barriers, face masks) to adequately protect themselves. Resettled refugees also need safe urban parks and playgrounds to exercise, play, and socialize outside of their homes, keep children off busy streets, and promote a greater sense of community. Community leaders continue to build these opportunities, but since the start of the COVID-19 pandemic, it has been difficult to create safe, recreational spaces while effectively implementing social distancing, among other protective measures.

\section{Living Conditions and Caring for Family}

During the COVID-19 pandemic, refugees in the USA are at higher risk of getting sick because of subpar living conditions (Centers for Disease Control and Prevention, n.d.). It can become difficult to isolate those who are ill or asymptomatic carriers of COVID-19 from the rest of the multigenerational family, who may be living together. Grocery stores and healthcare services such as pharmacies can be difficult to access without public or personal transportation, or bilingual delivery services. And, for newer resettled refugees who have not yet been integrated into the community, having support systems to help care for the family and provide access to needed services can be a challenge (Centers for Disease Control and Prevention, n.d.). With multiple ill persons in the same household, the primary caregiver, who is either ill themselves or at great risk for becoming ill, can become overburdened. This may lead to distress, heightened anxiety, and depression.

\section{Education}

\section{Literacy and Language}

Resettled Bhutanese refugees also experience communication barriers which impact their ability to find work, get to know others, network, and receive essential support. Approximately one third of Bhutanese refugees are fluent in English (Hauck et al. 2014), and an Ohio research poll found that $62 \%$ of this population experienced language barriers (Adhikari et al. 2015). This is especially problematic among adults over the age of thirty, who have greater difficulty learning and communicating in English (Pulla 2016). Ellis et al. (2015) found that female Bhutanese refugees had heightened stressors related to illiteracy, family conflict, and separation from family, which were associated with feeling burdensome or alienated from family.

\section{Schooling and Training}

Due to extensive agricultural farming in Bhutan, as well as life in the Nepali camps, many resettled Bhutanese refugees come to the USA without any formal schooling. Misra et al. (2016) identified that $43 \%$ of Bhutanese refugees never attended school; 
almost $80 \%$ did not have a high school education; and only $4 \%$ had attended a college. Without education and a command of the English language, it is difficult to find work in the USA, in addition to facing such barriers as understanding legal, healthcare, and support systems to gain access to basic necessities for survival and security. Likewise, poor economic stability often requires many adolescents and adults to drop out of school to work, significantly impeding opportunities to pursue education in the USA. Unfortunately, because many resettled refugees work at unskilled jobs, they are less likely to have job security, especially during this current pandemic when unemployment is rising.

\section{Communication and Education Technology}

There are many resettled refugees who do not speak or read English—or who are still learning English - that are not acquiring COVID-19 information from the news, English-based websites, or from COVID-19 hotlines, which are typically in English and Spanish. Community social media sites, leaders, health professionals, and community advocacy groups are thus tasked with providing accurate and ongoing information to the Bhutanese. Those who are able to translate within the Bhutanese community try to unpack the flood of information and relay best practices to protect their community members from this life-threatening infectious disease (e.g., social distancing, wearing of masks).

For resettled refugees who are currently enrolled in school, distance learning means that students are likely unable to receive the same focused attention by educators as was experienced prior to the pandemic. From learning English to preparing for college or trade school, online education can be a detriment to this population, especially when parents are unable to provide the necessary guidance due to language barriers, essential employment, illness, or other family obligations. One example of community education on COVID-19 can be found in a Boston College video series presentation titled "Schooling at Home." In this video, Ramesh Gautam, a Bhutanese educator, high school teacher, and founder of bhutaneseliterature. com, provides additional tips for parents to help their children learn at home. While tutoring services might be available through public school systems, not all schools have such services; they can be costly, and Nepali-speaking tutors can be hard to find.

\section{Nutrition and Exercise}

\section{Hunger and Addiction}

Difficulty of dietary acculturation can additionally contribute to negative physical and mental health outcomes among resettled Bhutanese refugees. Previously in Bhutan, traditional diets consisted of rice, vegetables, and lentil or pea curry (Kiptinness and Dharod 2011). Resettling in the USA, however, provides many new foods and dietary choices, including the cheaper, calorie-dense foods which often 
replace the traditionally nutrient-dense foods (Kiptinness and Dharod 2011). These cheaper, calorie-dense foods are often purchased as a result of economic instability, lack of health education and understanding, and the USA's social popularity surrounding these foods. Although many resettled Bhutanese still eat their traditional foods, according to the dietary survey among resettled Bhutanese refugees in Houston, Texas, $72 \%$ of resettled Bhutanese individuals reported drinking soda, with 20\% drinking everyday (Misra et al. 2016). Anecdotally, we have found a significant increase in use of soda (particularly cola) upon resettling to the USA and are now finding our refugees struggling with dental caries and other negative health effects, including mental illness emerging from these health stressors.

Though food support can be ascertained through the Supplemental Nutrition Assistance Program (SNAP) and the supplemental nutrition program for Women, Infants, and Children (WIC), these programs only allow for resettled families to purchase inexpensive staple foods, which can lack proper nutrition. Lack of nutritious foods and decreased physical activity often leads to various chronic health conditions which are common among the resettled Bhutanese refugees. These chronic health conditions among the resettled Bhutanese have been identified as dizziness, high blood pressure, arthritis, foot care problems, swelling and inflammation of joints, and cholesterol problems. This poor physical health is closely linked with mental health as it is associated with perceived burdensomeness and thwarted belongingness among the resettled Bhutanese (Ellis et al. 2015).

Refugee children are typically able to get lunch at school through school meal programs offered in the USA (Kiptinness and Dharod 2011); however, these programs are of no assistance during the COVID-19 pandemic, as school buildings have shut down and moved to online learning. Resettling in the USA has also led to a decrease in physical activity for Bhutanese families and, as such, can contribute to poor physical and mental health (Kiptinness and Dharod 2011). This may be due to neighborhoods and housing that do not allow for safe outdoor recreation, as well as cultural differences in how to be physically active (i.e., farming and gardening, compared to running on a treadmill). When surveyed, $41 \%$ of resettled Bhutanese individuals reported exercising, compared to $51 \%$ in the US total population.

During the COVID-19 pandemic, access to nutritious foods and opportunities for physical activity have been limited and addictions exacerbated. To reiterate, many have lost jobs or are at higher risk of getting sick as essential workers, making it difficult for families to purchase food during the pandemic. Additionally, depending on the state of residency, resettled Bhutanese refugees have been mandated (or strongly encouraged) to stay at home, reducing opportunities to go outside and be physically active.

Addiction, such as alcohol abuse, further contributes to mental health and suicide among resettled Bhutanese refugees (Schininà et al. 2011) and is escalating during COVID-19. Harmful alcohol consumption was a challenge for many refugees in Nepali refugee camps where easy access to alcohol, combined with few opportunities for work, education, and recreation, led many to drink excessively (Luitel et al. 2013; Mirza et al. 2018). This has continued to be a difficulty for many Bhutanese refugees in the USA, where stressors of acculturation, work, family conflict, etc. combine with easy access to alcohol, often resulting in alcohol abuse (Adhikari et al. 2015; Mirza 
et al. 2018). Before the pandemic, studies had shown daily alcohol use up to $20 \%$ among Nepali-Bhutanese refugees - in addition to $25 \%$ currently smoking cigarettes, 23\% using smokeless tobacco, and 28\% as dual tobacco users (Adhikari et al. 2015). Although current rates among the resettled Nepali-Bhutanese refugees are unknown, the COVID-19 pandemic has led to increased social isolation, decreased employment and recreation, and less ability to meet with healthcare providers, therefore culminating in worsened mental health, increased drinking and relapse, and an increased projection of suicide (Da et al. 2020).

\section{Community and Social Context}

\section{Social Integration}

Integrating oneself with new cultural and societal norms tends to cause high levels of acculturative stress and correlated depression and anxiety levels (Lumley et al. 2018). This is true of the Bhutanese refugees whose beautiful culture, language, beliefs, and traditions can lead to feelings of being vulnerable and diverse among others in the USA. This acculturation stress often leads to an uncertain sense of identity and cultural traditions (George 2012) and directly correlates with higher depression and anxiety levels (Lumley et al. 2018), particularly among females (Poudel-Tandukar et al. 2020). The Bhutanese refugees are very tight-knit and quick to help and support one another. They trust and depend on each other, and they are, for the most part, a very self-sufficient population when acclimated to their environments. Their strong unity and cultural differences lead many refugees to live close together in neighborhoods and communities where they feel more comfortable. All Bhutanese participants in one study reported living close to other Bhutanese families, which led to making strong social ties within their local ethnic communities, but few American friends beyond coworkers (Hauck et al. 2014). Although they may feel welcome within their local ethnic communities, difficulty making friends with other Americans may lead to feelings of social isolation. This is worrisome, as social isolation is a strong predictor of mental health disorders in refugee populations (Peterson et al. 2020).

Additional research shows devout Hinduism practiced by resettled Bhutanese refugees may correlate with increased environmental and social stress (Benson et al. 2011). Hindu religion is richly intertwined with the Bhutanese refugee culture and may conflict with Western culture and traditions and lead to questioning of self-identity, beliefs, and culture during and after resettlement. Devout Hindu Bhutanese refugees may need additional help through the resettling process to cope with acculturation stress and mental health concerns, particularly when places of worship are inaccessible or unavailable (especially during a pandemic).

\section{Discrimination and Support Systems}

Worldwide, since the start of the coronavirus pandemic, Asians and people of Asian descent have been the target of discrimination. According to a survey by 
Pew Research Center, Asian adults (58\%) explain that it is more common for people to express racist or racially insensitive views about people who are Asian than it was before the coronavirus outbreak, and approximately $40 \%$ of White, Black, and Hispanic adults say this is more common at the moment (Ruiz et al. 2020). About three-in-ten Asian adults (31\%) say they have been subject to slurs or jokes because of their race or ethnicity since the outbreak began (Ruiz et al. 2020). The Asian Pacific Policy \& Planning Council and Chinese for Affirmative Action group have been collecting reports about discrimination and hate directed at Asian community members since the start of the coronavirus pandemic. While most incidents of racism and harassment are verbal (i.e., Asians are blamed for COVID-19), 10-15\% of reported incidents include bodily harm and subsequent mental anguish in a surge of US hate crimes (Margolin 2020). Furthermore, social media has become a means to either discriminate against Asians and Asian-Americans or to fight against prejudice. Such discrimination has been seen to have a negative association with social support, which is directly associated with physical and mental health (Szaflarski and Bauldry 2019). Media outlets have been considered as one of the main factors contributing to discrimination and xenophobia (Aten 2020, IN: Croucher et al. 2020). As Asian people, Bhutanese refugees can be the subject of pervasive discrimination that continues to impact their mental well-being and are in need of support systems such as family.

Risk factors in the family also play an important role in Bhutanese refugee mental health and suicide ideation. During resettlement, family separation, marriages, or death in the family significantly shift family dynamics, which often leads to family responsibilities being placed upon non-traditional family members. Consequently, these affected family members often experience greater distress, leading to overwhelming feelings of shame, failure, and suicidal ideation (Schininà et al. 2011). One study illustrated that mental health disorders can carry through multiple generations to correlate with psychological or well-being outcomes (Sangalang and Vang 2017). Brown et al. (2019) found that shifting dynamics and conflict within families might be suicidal risk factors, and communication barriers make it difficult for those contemplating suicide to express how they are feeling. Additional family risk factors include history of suicide or attempt in the close family, shifts of family responsibilities onto non-traditional providers, and family conflicts, which can all lead to depression, psychosis, and suicide (Schininà et al. 2011).

Social support programs, charities, and other agencies help resettled Bhutanese families; however, anecdotally, as a hard-working and independent people, they do not want to ask for help. Past traumas and abuse have also led to distrust of those outside of their immediate community, and language barriers make it even more difficult to build trust. Surveys show that $70 \%$ of resettled Bhutanese families claimed little help from charities or other agencies, and 69.5\% claimed little help from the state and national governments (Adhikari et al. 2015). This low social support from community and government has been identified as a risk factor for suicidal ideation, alongside other risk factors-including symptoms of anxiety, depression, and PTSD, not being a provider of the family, traumatic events, post-migration difficulties, decreased employment, and fewer educational opportunities (Ao et al. 2016). 


\section{Healthcare System}

\section{Health Coverage}

Bhutanese refugees do not always receive essential culturally appropriate mental health support and treatment because of challenges in accessing healthcare, and language and cultural barriers. When resettled Bhutanese refugees are asked what they would do if they were seriously thinking about committing suicide, only $21 \%$ said that they would visit a doctor, $16 \%$ said that they would visit a mental health professional, and $2 \%$ said that they would use a crisis hotline (Ao et al. 2016). To better support the mental health of Bhutanese refugees, many communities prioritize greater access to healthcare. Though a vital step in the right direction, researchers Stanley and John Mann (2020) found that an estimated $40 \%$ of individuals who die by suicide accessed primary care services the month prior to suicide, illustrating that these services are not sufficient in preventing suicide and improving mental health.

Resettled Bhutanese refugees also cite the lack of healthcare insurance coverage and access to healthcare services as a barrier to care and treatment (Hauck et al. 2014). Because Bhutanese participants received lower standards of care before coming to the USA, their complaints about US healthcare centered on cost and convenience (Hauck et al. 2014). In regard to COVID-19, many refugees lack sufficient financial support and insurance to pay for their care. The CDC reports that after their short-term health insurance expires in the early resettlement period, up to $50 \%$ of refugees may be uninsured (Centers for Disease Control and Prevention, n.d.). Misra et al. (2016) found that $61 \%$ had some type of health coverage, and only $2 \%$ had insurance from their employer.

While some immigrants, who are given "refugee" status by the government, may be entitled to Medicaid and other public health benefits, most immigrants and asylum seekers are forced to rely on emergency-only medical service (Makhlouf 2019). Even with the availability of federal programs, immigrants are still disproportionately uninsured compared to US citizens. Makhlouf (2019) found that $18 \%$ of lawfully present adults (both refugees and all other non-citizens) lacked health insurance in 2015 , compared to only $11 \%$ of US citizens; the same study found that $13 \%$ of lawfully present children lacked health insurance in 2015 , while only $5 \%$ of US citizen children lacked insurance.

\section{Mental Health Stigma}

The cultural stigma placed on mental health may discourage many from disclosing mental health problems and seeking medical help. A recent study of 201 resettled Bhutanese refugee adults living in Columbus, Ohio, helps highlight the vast impact of stigma: $57.7 \%$ said that the term "mental illness" makes them feel embarrassed; $61.2 \%$ were afraid of what their boss, friends, and others would think if they were diagnosed with a mental illness; 55.2\% felt shame seeing a mental health counselor; over $71 \%$ thought they would be seen in a less favorable way going to a mental health counselor; and $54.7 \%$ thought those who received psychological help tended 
to be disliked (MacDowell et al. 2020). Approximately 62\% of Bhutanese refugees believe mental illness is unlikely to be cured even with treatment (MacDowell et al. 2020), compared to only $5.3 \%$ of general Ohio residents who disagree that treatment could help people with mental illness (Kobau et al. 2012). This vast difference in stigma may help to explain why few refugees seek out the help of mental health providers (Schininà et al. 2011). According to Adhikari et al. (2015), only 28\% of Bhutanese refugees in Ohio were interested in seeking help from a health professional, further highlighting the importance of providing culturally and linguistically appropriate outreach and counseling.

\section{Provider Linguistic Barriers}

Linguistic barriers between healthcare professionals and Bhutanese refugees make it difficult for them to receive mental healthcare treatment. Language interpreters are not always available, and often concepts such as self-care and mental health do not translate between English and Nepali languages. This leads to a clear lack of informed consent for healthcare procedures among refugees who speak another language (Borowski et al. 2019). Hospitals and healthcare providers strive to assist the Bhutanese refugees through language interpreters, and though this may be an initial step in the right direction, current research shows that professional interpreters and migrant health workers assisting refugees may not adequately address the social barriers these refugees encounter daily, and these refugees often feel unsafe in the healthcare setting (Harrison et al. 2020). Additionally, social services often completely lack Nepali translation services, making it difficult to receive help from any referral social support services. But the language barriers do not end with social services, as there is an overwhelming shortage of Nepali interpreters in the USA. For example, as of April 2020, the Supreme Court of Ohio listed 59 Spanish interpreters on its roster of court interpreters, but not a single Nepali interpreter was listed (Supreme Court of Ohio 2020). Therefore, if a Nepali-speaking refugee ends up in one of Ohio's many courts, having access to a qualified interpreter is rare. From social services to the medical and legal fields, the availability of trained interpreters is crucial to achieving public health justice.

\section{Legal System}

\section{The Necessity of Legal Resources}

Refugees deserve legal protection from every nation-state in which they seek sanctuary. It is not enough for a country's legal system to allow refugees to merely exist within its borders; rather, a country's legal system must be working to ensure that refugees are allowed to thrive within its borders. One confounding problem, however, is that there are potential legal barriers related to each of the SDIMH. From securing stable employment to obtaining adequate healthcare, a refugee's chance at a successful resettlement depends wholly upon the legal framework of their host 
state (Costa 2006). The rights and benefits afforded to refugees vary by country, according to the laws of each nation. Quite directly, legal systems have an impact on the mental health of resettled refugees.

Throughout the resettlement process, refugees are forced to navigate foreign legal and administrative systems. Even after resettling in their respective host countries, refugees may continue to face a multitude of legal issues related to immigration status, civil matters, criminal matters, and rights and benefits (Costa 2006; UNHCR 2010). To ensure that refugees are equipped to handle challenges within the legal system, access to legal resources is a necessity.

\section{Access to Legal Resources}

While legal assistance is crucial for refugee populations, there seems to be a shortage of available resources. Necessary resources include competent lawyers, interpreters/translators, money for legal fees and related costs, transportation to/from proceedings, and telecommunication equipment (especially in the age of COVID-19). One of the main barriers to access is ability to pay. In large part, non-governmental organizations (NGOs) and pro bono attorneys have accepted the responsibility of providing legal services to refugees. However, NGOs dedicated to refugee advocacy have limited funding and these services can become very expensive, especially if they lead to court proceedings. And there is a limited availability of pro bono lawyers who are competent to handle immigration cases-particularly in smaller cities and rural areas (Eagly and Shafer 2016). As Eagly and Shafer $(2016,15)$ point out in their special report on "Access to Counsel in Immigration Court", “...the vast majority of immigration attorneys who do take cases in these remote courts must travel long distances to attend court hearings, further hindering access to counsel by increasing the costs associated with providing legal services". Additionally, when there is a scarcity of interpreters in the area, language and cultural barriers prevent refugees from obtaining legal assistance (Costa 2006). While family members and friends often act as interpreters for Bhutanese refugees, there are clear limitations when relying upon family and friends for language interpretation in legal affairs. ${ }^{4}$

\section{Legal Resources and Refugee Status}

In the age of COVID-19, there are even greater obstacles to accessing counsel and navigating the legal landscape. For starters, many professionals and agencies are now working from home, relying on technology and telecommunication equipment not readily available to some resettled refugees. For those refugees forced to continue attending in-person consultations and hearings, their health and safety is placed at risk in exchange for exercising their legal rights. To make

\footnotetext{
${ }^{4}$ Examples of limitations include the following: family members/friends may not be able to adequately explain legal concepts to refugees in their native language; a refugee might be dealing with a private matter that they do not feel comfortable sharing with others; cultural differences (and values) cannot always be accounted for and interpreted accurately.
} 
matters more complicated, many immigration processes around the world have either been slowed down or put on hold altogether. On March 17, 2020, for example, the UNHCR and the International Organization for Migration suspended travel by refugees to their resettlement countries (Loweree et al. 2020). In the USA, all in-person services were suspended by U.S. Citizenship and Immigration Services during April-June of 2020. As explained by Loweree et al. (2020), there is an unnecessary delay for tens of thousands of immigrants to become US citizens, which may affect work authorization, access to healthcare, and other rights that tend to impact a person's mental well-being.

This is a major issue, as legal "refugee" status places various limitations on a newly resettled immigrant. State assistance programs, for example, have different eligibility requirements that might not be met by all refugees; moreover, assistance varies by state and is typically limited to three to five years. Refugees who do not qualify for standard welfare programs in the USA (TANF, Medicaid, etc.) are eligible for Refugee Cash Assistance and Refugee Medical Assistance programs offered by the Office of Refugee Resettlement; however, these benefits are only available during a refugee's first eight months in the USA, starting from their date of arrival. While refugee status allows immigrants to apply for unemployment benefits, the application process can be cumbersome-especially for someone with limited English proficiency and/or limited computer literacy.

Finally, it is important to note that a person's refugee status subjects them to deportation for the conviction of certain crimes committed in the USA. This presents several ethical concerns, as the Bhutanese refugee population often lacks access to legal representation and qualified Nepali interpreters. If there is a miscommunication or misunderstood guilty plea, a refugee could be at risk for deportation. Relatedly, in light of the increasing rate of hate crimes committed against Asian people in the USA, it is of utmost importance that law enforcement be able to effectively communicate with Bhutanese refugees so that they can safely report hate crimes and threats of violence. Leaders of the legal community-from police officers to judges - ought to practice cultural awareness in order to better serve the growing refugee population.

\section{Conclusion}

It is evident from our extensive literature review that the systems currently in place, although helpful, do not provide enough resources and guidance to allow resettled Bhutanese refugees to thrive within our nation's borders. Refugees resettling in any nation require adequate healthcare coverage to address mental health crises; they require assistance to navigate a country's challenging legal systems; they require compassion and understanding from their neighbors; and so much more. In our next article, "Striving toward Social Justice for Refugee Mental Health in the Age of COVID" (Yozwiak et al. 2021), we consider the many ways to fully support this refugee community and provide solutions for achieving public health justice. 
Acknowledgements We would like to thank Asia, Inc., and its members for providing us with additional informational support in this project.

Author Contribution All authors contributed to the development of this manuscript: literature review, theoretical analysis, presentation of novel ideas, and editing.

Funding This project was partially supported with a summer research fellowship stipend for Tanner McGuire, 2nd year medical student, who is the lead author on this manuscript. The Fellowship stipend comes from the Office of Research and Sponsored Programs, Northeast Ohio Medical University, and is dedicated for mentoring medical student research.

\section{Declarations}

Conflict of Interest The authors declare no competing interests.

\section{References}

Adhikari, Surendra Bir, Kelly Yotebieng, Jhuma N. Acharya, and Jaclyn Kirsch. 2015. Epidemiology of mental health, suicide and post-traumatic stress disorder among Bhutanese refugees in Ohio, 2014. Ohio Department of Mental Health and Addiction Services. https://mha.ohio.gov/Portals/0/assets/ HealthProfessionals/About\%20MH\%20and\%20Addiction\%20Treatment/TIC/ResourceLibrary/ Bhutanese-Refugee_MH_Suicide_PTSD_Report_April\%202015.pdf. Accessed 14 August 2020.

Ao, Trong, Sharmila Shetty, Teresa Sivilli, Curtis Blanton, Heidi Ellis, Paul L. Geltman, Jennifer Cochran, Eboni Taylor, Emily W. Lankau, and Barbara Lopes Cardozo. 2016. Suicidal ideation and mental health of Bhutanese Refugees in the United States. Journal of Immigrant and Minority Health 18 (4): 828-835. https://doi.org/10.1007/s10903-015-0325-7.

Artiga, Samantha, and Elizabeth Hinton. 2018. Beyond health care: the role of social determinants in promoting health and health equity. Kaiser Family Foundation, 10 May 2018. https://www.kff.org/dispa rities-policy/issue-brief/beyond-health-care-the-role-of-socialdeterminants-in-promoting-healthand-health-equity/. Accessed 14 August 2020.

Aten, Jaime D. 2020. Long-term Covid-19 mental health effects for Asian Americans. Psychology Today, 16 April 2020. https://www.psychologytoday.com/us/blog/hope-resilience/202004/long-term-covid19-mental-health-effects-asian-americans. Accessed 6 September 2020.

Aultman, Julie M. 2019. How should health care professionals address social determinants of refugee health? AMA Journal of Ethics 21 (3): 223. https://doi.org/10.1001/amajethics.2019.223.

Australian Survey Research Group. 2010. Settlement outcomes of new arrivals. Report of findings. Canberra: Department of Immigration and Citizenship.

Benson, G. Odessa., Fei Sun, David R. Hodge, and David K. Androff. 2011. Religious coping and acculturation stress among Hindu Bhutanese: A study of newly-resettled refugees in the United States. International Social Work 55 (4): 538-553. https://doi.org/10.1177/0020872811417474.

Blanck, Heidi Michels, Barbara A. Bowman, Mary K. Serdula, Laura Kettel Khan, William Kohn Khan, and Bradley A. Woodruff. 2002. Angular stomatitis and riboflavin status among adolescent Bhutanese refugees living in southeastern Nepal. American Journal of Clinical Nutrition 76 (2): 430-435. https://doi.org/10.1093/ajcn/76.2.430.

Blizzard, Brittany, and Jeanne Batalova. 2019. Refugees and asylees in the United States. Migration Policy Institute, 13 June 2019. https://www.migrationpolicy.org/article/refugees-and-asylees-unitedstates-2018. Accessed 13 July 2020.

Borowski, Damaris, Uwe Koreik, Udo Ohm, Claudia Riemer, and Niels Rahe-Meyer. 2019. Informed consent at stake? Language barriers in medical interactions with immigrant anaesthetists: A conversation analytical study. BMC Health Services Research 19 (1): 597. https://doi.org/10.1186/ s12913-019-4389-2.

Brown, Felicity L., Tej Mishra, Rochelle L. Frounfelker, Emily Bhargava, Bhuwan Gautam, Aakriti Prasai, and Theresa Betancourt. 2019. 'Hiding their troubles': a qualitative exploration of suicide in Bhutanese refugees in the USA. Global Mental Health 6: E1. https://doi.org/10.1017/gmh.2018.34. 
Capps, Randy, Kathleen Newland, Susan Fratzke, Susanna Groves, Gregory Auclair, Michael Fix, and Margie McHugh. 2015. The integration outcomes of U.S. refugees: successes and challenges. Washington, DC: Migration Policy Institute. https://www.migrationpolicy.org/research/integration-outco mes-us-refugees-successes-and-challenges. Accessed 6 September 2020.

Centers for Disease Control and Prevention. 2008. Malnutrition and micronutrient deficiencies among Bhutanese refugee children-Nepal, 2007. Morbidity and Mortality Weekly Report 57 (14): 370373. https://www.cdc.gov/mmwr/preview/mmwrhtml/mm5714a3.htm. Accessed 17 August 2021.

Centers for Disease Control and Prevention. n.d. COVID-19 in newly resettled refugee populations. https://www.cdc.gov/coronavirus/2019-ncov/need-extra-precautions/refugee-populations.html. Accessed 25 July 2020.

Costa, Rosa da. 2006. Rights of refugees in the context of integration: legal standards and recommendations. Geneva: United Nations High Commissioner for Refugees. https://www.unhcr.org/en-us/prote ction/globalconsult/44bb90882/12-rights-refugees-context-integration-legalstandards-recommenda tions.html. Accessed 30 July 2020.

Croucher, Stephen M., Thao Nguyen, and Diyako Rahmani. 2020. Prejudice toward Asian Americans in the Covid-19 pandemic: the effects of social media use in the United States. Frontiers in Communication 5: 39. https://doi.org/10.3389/fcomm.2020.00039.

Da, Ben L., Gene Young Im, and Thomas D. Schiano. 2020. COVID-19 hangover: A rising tide of alcohol use disorder and alcohol associated liver disease. Hepatology 72 (3): 1102-1108. https://doi.org/ 10.1002/hep.31307.

Davis, Jacqueline, Kerrie Mengersen, Sarah Bennett, and Lorraine Mazerolle. 2014. Viewing systematic reviews and meta-analysis in social research through different lenses. Springerplus 3: 511. https:// doi.org/10.1186/2193-1801-3-511.

Eagly, Ingrid, and Steven Shafer. 2016. Access to counsel in immigration court. American Immigration Council. https://www.americanimmigrationcouncil.org/sites/default/files/research/access_to_couns el_in_immigration_court.pdf. Accessed 1 August 2020.

Ellis, B. Heidi., Emily W. Lankau, Trong Ao, Molly A. Benson, Alisa B. Miller, Sharmila Shetty, Barbara Lopes Cardozo, Paul L. Geltman, and Jennifer Cochran. 2015. Understanding Bhutanese refugee suicide through the interpersonal-psychological theory of suicidal behavior. American Journal of Orthopsychiatry 85 (1): 43-55. https://doi.org/10.1037/ort0000028.

Frelick, Bill. 2011. For Bhutan's refugees, there's no place like home. The World, 30 March 2011. https:// www.pri.org/stories/2011-03-30/bhutan-s-refugees-there-s-no-place-home. Accessed 9 September 2020.

Galvin, Gaby. 2018. Where do refugees settle in America? U.S. News \& World Report, 10 January 2018. https://www.usnews.com/news/best-states/slideshows/10-states-that-took-the-most-refugees-in2017? slide=9. Accessed 13 July 2020.

George, Miriam. 2012. Migration traumatic experiences and refugee distress: Implications for social work practice. Clinical Social Work Journal 40: 429-437. https://doi.org/10.1007/s10615-012-0397-y.

Gostin, Lawrence O., and Madison Powers. 2006. What does social justice require for the public's health? Public health ethics and policy imperatives? Health Affairs 25 (4): 1053-1060. https://doi.org/10. 1377/hlthaff.25.4.1053.

Harrison, Reema, Merrilyn Walton, Upma Chitkara, Elizabeth Manias, Ashfaq Chauhan, Monika Latanik, and Desiree Leone. 2020. Beyond translation: Engaging with culturally and linguistically diverse consumers. Health Expectations 23 (1): 159-168. https://doi.org/10.1111/hex.12984.

Hauck, Fern R., Elsbeth Lo, Anne Maxwell, and P. Preston Reynolds. 2014. Factors influencing the acculturation of Burmese, Bhutanese, and Iraqi refugees into American society: Cross-cultural comparisons. Journal of Immigrant \& Refugee Studies 12 (3): 331-352. https://doi.org/10.1080/15562 948.2013.848007.

Ikram, Zubia, 2005. Bhutanese refugees in Nepal: an analysis. Pakistan Horizon 58 (3): 101-116. https:// www.jstor.org/stable/41394105. Accessed 18 June 2020.

Kawohl, Wolfram, and Carlos Nordt. 2020. COVID-19, unemployment, and suicide. Lancet Psychiatry 7 (5): 389-390. https://doi.org/10.1016/S2215-0366(20)30141-3.

Kim, Angela, Kimberly Witt, Bonnie Burch, and Alysia Jenson. 2017. Forced acculturation \& the crushed American dream: The Gap between the UN Departure Preparation of Bhutanese Refugees and the Resettlement Policies of the United States. Middle East Review of Public Administration 3 (2). https://merpa.scholasticahq.com/api/v1/articles/1835-forced-acculturation-the-crushed-ameri can-dream-thegap-between-the-u-n-departure-preparation-of-bhutanese-refugees-and-the-reset tlement-policies-of-the-united-states.pdf. Accessed 21 August 2021. 
Kiptinness, Catherine, and Jigna M. Dharod. 2011. Bhutanese refugees in the United States: Their dietary habits and food shopping practices upon resettlement. Journal of Hunger \& Environmental Nutrition 6 (1): 75-85. https://doi.org/10.1080/19320248.2011.551034.

Kobau, Rosemarie, Matthew M. Zack, Cecily Luncheon, John P. Barile, Chris Marshall, Thomas Bornemann, Emeline McConnell Otey, et al. 2012. Attitudes toward mental illness: results from the behavioral risk factor surveillance system. Atlanta, GA: Centers for Disease Control and Prevention. https://stacks.cdc.gov/view/cdc/22179. Accessed 17 August 2021.

Krogstad, Jens Manuel. 2019. Key facts about refugees to the U.S. Pew Research Center, 7 October 2019. https://www.pewresearch.org/fact-tank/2019/10/07/key-facts-about-refugees-to-the-us/\#: : text $=$ Since $\% 20$ fiscal $\% 202002 \% 2$ C \% 20California \%20has, $\% 20$ and $\% 20$ Florida $\% 20(48 \% 2$ C 700$)$. Accessed 13 July 2020.

Loweree, Jorge, Aaron Reichlin-Melnick, and Walter A. Ewing. 2020. The impact of COVID-19 on noncitizens and across the U.S. immigration system. American Immigration Council. https://www. americanimmigrationcouncil.org/sites/default/files/research/the_impact_of_covid-19_on_nonci tizens_and_across_the_us_immigration_system.pdf. Accessed 1 August 2020.

Luitel, Nagendra, Mark Jordans, Adrianna Murphy, Bayard Roberts, and Jim McCambridge. 2013. Prevalence and patterns of hazardous and harmful alcohol consumption assessed using the AUDIT among Bhutanese refugees in Nepal. Alcohol and Alcoholism 48 (3): 349-355. https://doi.org/10.1093/ alcalc/agt009.

Lumley, Mia, Mary Katsikitis, and Dixie Statham. 2018. Depression, anxiety, and acculturative stress among resettled Bhutanese refugees in Australia. Journal of Cross-Cultural Psychology 49 (8): 1269-1282. https://doi.org/10.1177/0022022118786458.

MacDowell, Hannah, Sudarshan Pyakurel, Jhuma Acharya, Diane Morrison-Beedy, and Jennifer Kue. 2020. Perceptions toward mental illness and seeking psychological help among Bhutanese refugees resettled in the U.S. Issues in Mental Health Nursing 41 (3): 243-250. https://doi.org/10.1080/ 01612840.2019 .1646362 .

Makhlouf, Medha D. 2019. Health justice for immigrants. University of Pennsylvania Journal of Law \& Public Affairs 4: 235. https://scholarship.law.upenn.edu/jlpa/vol4/iss2/3/. Accessed 19 August 2021.

Margolin, Josh. 2020. FBI warns of potential surge in hate crimes against Asian Americans amid coronavirus. ABC News, 27 March 2020. https://abcnews.go.com/US/fbi-warns-potential-surge-hatecrimes-asian-americans/story?id=69831920. Accessed 6 September 2020.

Mills, Edward, Sonal Singh, Brenda Roach, and Stephanie Chong. 2008. Prevalence of mental disorders and torture among Bhutanese refugees in Nepal: A systemic review and its implications. Medicine, Conflict and Survival 24 (1): 5-15. https://doi.org/10.1080/136Policy23690701775171.

Mirza, Mansha Q., Elizabeth A. Harrison, Hui-Ching Chang, Corrina D. Salo, and Dina Birman. 2018. Community perspectives on substance use among Bhutanese and Iraqi refugees resettled in the United States. Journal of Prevention \& Intervention in the Community 46 (1): 43-60. https://doi.org/ 10.1080/10852352.2018.1385956.

Misra, Sanghamitra M., Vishnu P. Nepal, Deborah Banerjee, and Angelo P. Giardino. 2016. Chronic health conditions, physical activity and dietary behaviors of Bhutanese refugees: A Houston-based needs assessment. Journal of Immigrant and Minority Health 18 (6): 1423-1431. https://doi.org/10. 1007/s10903-015-0282-1.

National Immigration Forum. 2019. Fact sheet: U.S. refugee resettlement. https://immigrationforum. org/article/fact-sheet-u-s-refugeeresettlement/\#: :text=Refugees $\% 20$ have $\% 20$ been $\% 20$ resettled $\%$ 20in,most\%20refugees\%20in\%20FY\%202018. Accessed 13 July 2020.

Ohio Department of Job and Family Services. 2020. Coronavirus and unemployment insurance resource hubs. https://unemploymenthelp.ohio.gov/. Accessed 9 September 2020.

Peterson, Cynthia, Kalpana Poudel-Tandukar, Kirk Sanger, and Cynthia S. Jacelon. 2020. Improving mental health in refugee populations: A review of intervention studies conducted in the United States. Issues in Mental Health Nursing 41 (4): 271-282. https://doi.org/10.1080/01612840.2019. 1669748.

Poudel-Tandukar, Kalpana, Cynthia S. Jacelon, Elizabeth Bertone-Johnson, Bhuwan Gautam, Paula H. Palmer, and Steven D. Hollon. 2020. Coping strategies and stress among resettled Bhutanese adults in Massachusetts. American Journal of Orthopsychiatry 90 (4): 502-509. https://doi.org/10.1037/ ort0000453.

Pulla, Venkat, ed. 2016. The Lhotsampa people of Bhutan: resilience and survival. New York: Palgrave Macmillan. https://doi.org/10.1057/9781137551429. 
Refugee Council USA. n.d. Resettlement process. https://rcusa.org/resettlement/resettlement-process/. Accessed 13 July 2020.

Reiffers, Relinde, Ram Dahal, Suraj Koirala, Renee Gerritzen, Nawaraj Upadhaya, Nagendra Luitel, Shaligram Bhattarai, and Mark Jordans. 2013. Psychosocial support for Bhutanese refugees in Nepal. Intervention 11 (2): 169-179. https://doi.org/10.1097/wtf.0b013e32835e368c.

Rizal, Dhurba. 2004. The unknown refugee crisis: Expulsion of the ethnic Lhotsampa from Bhutan. Asian Ethnicity 5 (2): 151-177. https://doi.org/10.1080/1463136042000221861.

Ruiz, Neil G., Juliana Menasce Horowitz, and Christine Tamir. 2020. Many Black, Asian Americans say they have experienced discrimination amid coronavirus. Pew Research Center, 1 July 2020. https:// www.pewsocialtrends.org/2020/07/01/many-black-and-asianamericans-say-they-have-experienceddiscrimination-amid-the-covid-19-outbreak/. Accessed 6 July 2020.

Sangalang, Cindy C., and Cindy Vang. 2017. Intergenerational trauma in refugee families: A systematic review. Journal of Immigrant \& Minority Health 19 (3): 745-754. https://doi.org/10.1007/ s10903-016-0499-7.

Schininà, Guglielmo, Sonali Sharma, Olga Gorbacheva, and Anit Kumar Mishra. 2011. Who am I? Assessment of psychosocial needs and suicide risk factors among Bhutanese refugees in Nepal and after the third country resettlement. International Organization for Migration (IOM). https://www. iom.int/sites/default/files/migrated_files/What-We-Do/docs/Mental-Health-Assessment-Nepal_ Final_11March.pdf. Accessed 18 June 2020.

Shrestha, Nirakar Man, Bhogendra Sharma, Mark Van Ommeren, Shyam Regmi, Ramesh Makaju, Ivan Komproe, Ganesh B. Shrestha, and Joop T. V. M. de Jong. 1998. Impact of torture on refugees displaced within the developing world: Symptomatology among Bhutanese refugees in Nepal. JAMA 280 (5): 443-448. https://doi.org/10.1001/jama.280.5.443.

Smith, Rebecca. 2020. Immigrant workers' eligibility for unemployment insurance. National Employment Law Project. https://www.nelp.org/publication/immigrant-workers-eligibility-unemploymentinsurance/. Accessed 9 September 2020.

Stanley, Barbara, and J. John Mann. 2020. The need for innovation in health care systems to improve suicide prevention. JAMA Psychiatry 77 (1): 96. https://doi.org/10.1001/jamapsychiatry.2019.2769.

Subedi, Anita, Dana S. Edge, Catherine L. Goldie, and Monakshi Sawhney. 2019. Resettled Bhutanese refugees in Ottawa: What coping strategies promote psychological well-being? Canadian Journal of Nursing Research 51 (3): 168-178. https://doi.org/10.1177/0844562119828905.

Supreme Court of Ohio. 2020. Roster of court interpreters by language. https://www.supremecourt.ohio. gov/JCS/interpreterSvcs/certification/rosters/language.pdf. Accessed 15 July 2021.

Szaflarski, Magdalena, and Shawn Bauldry. 2019. The effects of perceived discrimination on immigrant and refugee physical and mental health. Advances in Medical Sociology 19: 173-204. https://doi. org/10.1108/S1057-629020190000019009.

Thapa, Suraj B., Mark Van Ommeren, Bhogendra Sharma, Joop T. V. M. de Jong, and Edvard Hauff. 2003 Psychiatric disability among tortured Bhutanese refugees in Nepal. American Journal of Psychiatry 160 (11): 2032-2037. https://doi.org/10.1176/appi.ajp.160.11.2032.

U.S. Citizenship and Immigration Services. 2013. Refugee Eligibility Determination. USCIS. https:// www.uscis.gov/humanitarian/refugees-and-asylum/refugees/refugee-eligibility-determination\#: : text=Eligibility $\% 20$ for $\% 20$ refugee $\% 20$ status $\% 20$ is,resettlement $\% 20$ to $\% 20$ the $\% 20$ United $\% 20$ States. Accessed 13 July 2020.

U.S. Citizenship and Immigration Services. 2020. 6.3 refugees and asylees. USCIS. https://www.uscis. gov/i-9-central/handbook-for-employers-m-274/60-evidence-of-status-for-certain-categories/63refugees-and-asylees. Accessed 9 September 2020.

U.S. Department of Labor. n.d. How do I file for unemployment insurance? https://www.dol.gov/general/ topic/unemployment-insurance. Accessed 9 September 2020.

UNHCR. 2010. Convention and protocol relating to the status of refugees. United Nations High Commissioner for Refugees. https://www.unhcr.org/en-us/3b66c2aa10. Accessed 30 July 2020.

UNHCR. 2014. UNHCR resettlement handbook: country chapter-United States of America. United Nations High Commissioner for Refugees. http://www.unhcr.org/3c5e5a764.html. Accessed 9 September 2020.

UNHCR. 2019. Press statement: US ambassador Randy Berry visits Bhutanese Refugee settlements. United Nations Nepal Information Platform. http://un.org.np/headlines/Press-statement-us-ambas sador-randy-berry-visits-bhutanese-refugee-settlements. Accessed 13 July 2020.

UNHCR. n.d.a. Refugee Status Determination. United Nations High Commissioner for Refugees. https:// www.unhcr.org/en-us/refugeestatus-determination.html. Accessed 13 July 2020. 
UNHCR. n.d.b. Resettlement Data Finder. United Nations High Commissioner for Refugees. https://rsq. unhcr.org/en/\#C5oI. Accessed 14 July 2020.

Van Ommeren, Joop T. V. M., Mark de Jong, Sharma Bhogendra, Ivan Komproe, Suraj B. Thapa, and Etzel Cardeña. 2001. Psychiatric disorders among tortured Bhutanese refugees in Nepal. Archives of General Psychiatry 58 (5): 475-482. https://doi.org/10.1001/archpsyc.58.5.475.

Varia, Nisha, and Therese Caouette. 2003. Trapped by inequality: Bhutanese refugee women in Nepal. Human Rights Watch 15 (8). https://www.hrw.org/sites/default/files/reports/nepal0903full.pdf. Accessed 9 September 2020.

Woodruff, Bradley A., Heidi Michels Blanck, Laurence Slutsker, Susan T. Cookson, Mary Kay Larson, Arabella Duffield, and Rita Bhatia. 2006. Anaemia, iron status and vitamin A deficiency among adolescent refugees in Kenya and Nepal. Public Health Nutrition 9 (1): 26-34. https://doi.org/10. 1079/PHN2005825.

Yozwiak, Daniel, Tanner McGuire, and Julie M. Aultman. 2021. The mental health of refugees during a pandemic: striving toward social justice through social determinants of health and human rights. Asian Bioethics Review. https://doi.org/10.1007/s41649-021-00184-0.

Ziersch, Anna, and Clemence Due. 2018. A mixed methods systematic review of studies examining the relationship between housing and health for people from refugee and asylum seeking backgrounds. Social Science and Medicine 213: 199-219. https://doi.org/10.1016/j.socscimed.2018.07.045.

Ziersch, Anna, Clemence Due, Moira Walsh, and Kathy Arthurson. 2017. Belonging begins at home: housing, social inclusion and health and wellbeing for people from refugee and asylum seeking backgrounds. Adelaide: Flinders Press. https://anglicaresa.com.au/wpcontent/uploads/1749_Belon ging-begins-at-home-report_WEB-final.pdf. Accessed 25 July 2020.

Publisher's Note Springer Nature remains neutral with regard to jurisdictional claims in published maps and institutional affiliations. 